\title{
OS SURDOS COMO RÉUS OU VÍTIMAS NOS TRIBUNAIS DE JUSTIÇA: DIREITOS E DESAFIOS LEGAIS
}

\author{
The deaf as reporters or victims in the courts of justice: rights and legal challenges
}

Los sordos como reos o vítimas en los tribunales de justicia: derechos y retos legales

\author{
Adriano de Oliveira Gianotto ${ }^{1}$ \\ José Manfroi $^{2}$ \\ Heitor Romero Marques ${ }^{3}$
}

\begin{abstract}
Resumo
Neste estudo pretende-se mostrar a possibilidade de inclusão dos surdos em situação de réu ou vítimas em audiência jurídica. Determinou-se para o estudo, a pesquisa do tipo bibliográfica, baseada em distintos teóricos. Objetiva-se com este estudo, conhecer a inclusão de surdos em processos de execução legal. Perceber se os mesmos conhecem os recursos da lei e os direitos por seu estado de diversidade. A proposta pretende também conscientizar os surdos expostos no âmbito jurídico, para buscarem adequadamente os seus direitos. Objetiva-se também subsidiar os profissionais operadores do Direito, para que possam se qualificar para prestar um serviço mais eficaz, mais célere e mais justo dentro da dinâmica dos direitos humanos dos deficientes auditivos. A inclusão de surdos nos Tribunais de Justiça tem sido alvo de reflexões bem como de diagnósticos indevidos. Ora em vez os surdos são pronunciados como réus sem perspectiva de conhecimento de causa.
\end{abstract}

PALAVRAS-CHAVE: Surdos como réus ou vítimas; Tribunais de Justiça; Direitos e desafios;

\section{Resumen}

En ese estudio se pretende demostrar la posibilidad de inclusión de los sordos en situación de reo o víctimas en audiencia jurídica. Fue determinado para el estudio, la investigación bibliográfica, basada en distintos teóricos. Objetivase con ese estudio, conocer la inclusión de sordos en procesos de ejecución legal. Percibir se los mismos conocen los recursos de la ley y los derechos por su estado de diversidad. La propuesta pretende también concientizar los sordos expuestos en el ámbito jurídico, para buscaren adecuadamente sus derechos. Objetivase también subsidiar los profesionales operadores del Derecho, para que posan se cualificar para prestar un servicio más eficaz, más célere e más justo dentro de la dinámica de los derechos humanos de los con discapacidad auditiva. La inclusión de sordos en los Tribunales de Justicia tiene sido objetivo de reflexiones bien como de diagnósticos

\footnotetext{
${ }^{1}$ Licenciado em Pedagogia (Universidade Leonardo da Vinci); Especialista em LIBRAS e Educação Especial ênfase Deficiência Auditiva (Universidade Leonardo da Vinci); Mestrando em Desenvolvimento Local (UCDB); Proficiente em LIBRAS/MEC; Professor de LIBRAS pela Secretaria Municipal de Educação de Campo Grande; Responsável pela orientação do Trabalho de Conclusão de Curso de Pós Graduação em LIBRAS pela UCDB Virtual. Pesquisador na área de Educação de Surdos e LIBRAS em Mato Grosso do Sul. Email: adriatto@outlook.com

${ }^{2}$ Graduado em Filosofia (FUCMT). Mestre em educação (UFMS). Doutor em Educação (UNESP/Marília). Professor nos cursos de graduação e pós-graduação da UCDB. Professor pesquisador e coordenador de projetos de pesquisa no campo da diversidade cultural e grupos de inclusão social em Campo Grande. MS. Email: jmanfori@ terra.com.br

${ }^{3}$ Licenciado em Ciências e Pedagogia (FUCMT), Especialista em História e Filosofia da Educação (FUCMT), Mestre em Educação - formação de professores (UCDB) e Doutor em Desarrollo Local y planteamiento territorial (UCM - Espanha). Professor na UCDB em cursos de graduação, pós-graduação lato sensu e stricto sensu (Mestrado e Doutorado em Desenvolvimento Local). Desenvolve pesquisa na área de Direitos Humanos. Email: heiroma@ucdb.br
} 
indebidos. Ora en vez los sordos son pronunciados como reos sin perspectiva de conocimiento de causa.

PALAVRAS-CLAVE: Sordos cómo reos o víctimas; Tribunales de Justicia; Derechos y retos.

\begin{abstract}
This study intends to show the possibility of including the deaf in the situation of a defendant or victims in a legal hearing. It was determined the study, the research of the bibliographic type, based on different theorists. The objective of this study is to understand the inclusion of deaf people in legal enforcement processes. See if they know the resources of the law and the rights for their state of diversity. The proposal also aims to raise the awareness of deaf people exposed in the legal framework, to properly seek their rights. It is also intended to subsidize professional law professionals so that they can qualify to provide a more effective, faster and fairer service within the human rights dynamics of the hearing impaired. The inclusion of deaf people in the Courts of Justice has been the subject of reflections as well as undue diagnoses. But instead the deaf are pronounced like defendants without perspective of knowledge of cause.
\end{abstract}

KEYWORDS: Deaf as defendants or victims; Related searches; Rights and challenges;

\title{
INTRODUÇÃO
}

Neste estudo pretende-se mostrar a possibilidade de inclusão dos surdos em situação de réu ou vítimas em audiência jurídica. Determinou-se para o estudo, a pesquisa do tipo bibliográfica, baseada em distintos teóricos. Objetiva-se com este estudo, conhecer a inclusão de surdos em processos de execução legal. Perceber se os mesmos conhecem os recursos da lei e os direitos por seu estado de diversidade. A proposta pretende também conscientizar os surdos expostos no âmbito Jurídico, para buscarem adequadamente os seus direitos. Objetivase também subsidiar os profissionais operadores do Direito, para que possam se qualificar para prestar um serviço mais eficaz, mais célere e mais justo dentro da dinâmica dos direitos humanos dos deficientes auditivos.

A inclusão de surdos nos Tribunais de Justiça tem sido alvo de reflexões bem como de diagnósticos indevidos. Ora em vez os surdos são pronunciados como réus sem perspectiva de conhecimento de causa.

\section{O significado da inclusão}

A Constituição da República Federativa do Brasil de 1988, quando adota o princípio, da igualdade de condições para o acesso e permanência na escola, compreendido como efetivação do objetivo republicano de promover o bem de todos sem preconceito de origem, raça, sexo, cor, idade e quaisquer outras formas de discriminação, prevê uma sociedade com escolas abertas a todos, em qualquer etapa ou modalidade (BATTES, 2006, p. $05)$.

Durante décadas as pessoas surdas têm sido consideradas inúteis, por não participarem do mundo dos letrados. Isso caracteriza discricionariedade e, por conseguinte deve ser evitado. Quais são as oportunidades que e os deficientes surdos têm para verdadeiramente se igualarem em condições legais e terem os mesmos direitos que as demais pessoas? As reflexões sobre esta questão e conceitos constituem o objetivo desse estudo. Nesse sentido Ferreira e Guimarães (2003, p. 27) afirmam que: 
crença sobre sua suposta incapacidade. Esse quadro só poderá ser alterado a partir do momento em que seja alterada a condição de deficiência. Modificar-se, tomando em consideração também as potencialidades e possibilidades, e não apenas os defeitos e as limitações dessas pessoas.

Como dito, o presente estudo dá-se em função da necessidade permanente de atualização na dimensão dos Processos Criminais para julgamentos dos réus ou proteção às vítimas com surdez. Para isso busca-se a contribuição da sociologia contemporânea. Além disso, é necessária uma teoria crítica para compreender o percurso que os surdos fazem, enquanto integrantes da sociedade, no sentido de diminuir a criminalidade, a partir do interacionismo simbólico, de serem "normais", no contexto das relações estruturais e funcionais na atualidade social.

O método adotado na pesquisa que deu origem a este texto consistiu em refletir sobre a premissa de que todos são iguais perante a Lei, mas os procedimentos que os regem podem ser diferentes. Como procedimento metodológico na revisão bibliográfica, buscaram-se artigos de temáticas interdisciplinares para que houvesse maior compreensão do contexto sócio-histórico. Seguiu-se o seguinte roteiro: a) apresentação da teoria da inclusão como reflexão e compreensão dos equívocos praticados por Juízes, Advogados, Promotores, Defensores e Partes que consideram as pessoas surdas como "doidinho(a)s" ou pessoas que têm "problemas mentais"; b) particularmente os operadores do Direito regem a verificação da causa criminal dos indivíduos com surdez; fazendo tão somente uma descrição comum, em linhas gerais sobre todas as leis regentes, mas não de modo aplicado, exercendo um papel meramente formal; c) faz-se sucinta revisão sobre a doutrina jurídica, por meio do conhecimento do processo criminal; d) considera-se o julgamento dos surdos no âmbito processual criminalístico, em que se sinaliza a necessidade de mudanças, no sentido de repensar a função das penas e acima de tudo que realmente sejam conhecidas pelos Surdos.

Em vista do exposto há que se perguntar: a) somos todos iguais ou somos todos diferentes? b) Queremos ser iguais ou queremos ser diferentes? Houve um tempo em que a resposta se abrigava segura de si, no primeiro termo da disjuntiva. Já faz um quarto de século, porém, que a resposta se deslocou, nos seguintes termos:

[...] passamos a nos ver envoltos numa atmosfera cultural e ideológica inteiramente nova, na qual parece generalizar-se em ritmo acelerado e perturbador a consciência de que nós, humanos, somos diferentes de fato, porquanto temos cores diferentes na pele e nos olhos, temos sexo e gênero diferentes além de preferências sexuais diferentes, somos diferentes na origem familiar e regional, nas tradições e nas lealdades, temos deuses diferentes, diferentes hábitos e gostos, diferentes estilos ou falta de estilo; em suma, somos portadores de pertenças culturais diferentes. Mas somos também diferentes de direito. É o chamado "direito à diferença", o direito à diferença cultural, o direito de ser, sendo diferente (PIERUCCI, 1999, apud SANTOS, SANTOS FILHO; SANTOS OLIVEIRA, 2010, on line)

A inclusão reflexa das precisões sócio-históricas e educacionais da sociedade na busca de melhorias das dificuldades acerca da censura; do desenvolvimento, das potencialidades dos deficientes auditivos; da convivência social; do vínculo jurídico e do exercício da cidadania, baseada nos movimentos pela defesa dos direitos humanos que surgiu durante os anos de 1964 a 1968 nas distintas classes sociais, despertou na sociedade de forma expressiva, a ideia de inclusão. $O$ termo inclusão tão divulgado nos dias atuais e para alguns, tão inteiramente unido à educação, é algo tão antigo quanto à civilização, pois se começa com a vida (SANTOS, SANTOS FILHO; SANTOS OLIVEIRA, 2010, on line). 
Em termos gerais os movimentos sociais de luta pela construção da cidadania plena, desenvolvem ações que visam alcançar benefícios relacionados à saúde, educação e trabalho. Nesse contexto o deficiente auditivo sempre foi tratado de forma diferente, variando tão somente a maneira como cada movimento se comportou diante do ser "diferente". Em vista disso é possível afirmar que o deficiente auditivo se vê incluído, apesar de toda discriminação da qual sempre foi vítima.

Toda escola prepara o aluno para o mercado de trabalho, mas nem todos podem competir igualmente. A integração profissional das pessoas surdas no mercado de trabalho está com deficiência. Às vezes, por condições financeiras ou situações de despreparo do profissional da escola há fatos que colaboram para a exclusão das pessoas com surdez (SANTOS, SANTOS FILHO; SANTOS OLIVEIRA, 2010, on line).

Particularmente, no tocante ao quesito trabalho, a admissão de pessoas surdas ou com deficiência auditiva está ocorrendo sob três formas: 1) São admitidas por empresas que concordam em aceitar devido a legislação que obriga, mas o uso da LIBRAS não é respeitada, 2) São admitidos e contratados em órgãos públicos e empresas particulares, desde que apresentem qualificação profissional e consigam utilizar os espaços físicos e os equipamentos de trabalho sem nenhuma modificação. 3) São aceitas para trabalhar em empresas que os inserem em grupos longe dos demais funcionários e do público, geralmente, sem carteira assinada e/ou, se contratadas, sem promoções ao longo dos anos, pois alguns deficientes auditivos não possuem certificações como profissionais para exercerem os cargos (QUADROS, 2004 apud SANTOS, SANTOS FILHO; SANTOS OLIVEIRA, 2010, on line).

Nessa esteira de entendimento é importante enfatizar que as conquistas alcançadas até o momento, apesar de representarem significativos avanços, é preciso que os próprios deficientes auditivos aprendam a lutar por seus direitos, sem o que o restante da sociedade nada fará, incluindo o Sistema Judiciário e o Ministério Público, em suas esferas e instâncias de atuação.

\section{A garantia legal da inclusão}

É perfeitamente defensável a ideia de inclusão, enquanto contraponto da exclusão, visto que são termos que dependem dos referenciais de análise. No afã de trazer à baila a construção da cidadania plena, os movimentos sociais, ora em vez, atropelam princípios gerais a favor de particularidades culturais. Há segmentos sociais que se sentem excluídos por verem seus valores desrespeitados em nome do favorecimento de outros segmentos. Todavia, a regra geral deve ser a de que todos são portadores de direitos e correspondentemente de deveres. É isso que emana da Constituição da República Federativa do Brasil de 1988 e da Declaração Universal dos Direitos Humanos. Quando esses referenciais maiores forem contrariados, quando da efetivação nas particularidades individuais, é preciso que a sociedade reaja de forma efetiva, inclusive em termos formais, por meio de suas instituições. Via regra, são as pessoas deficientes, as que mais têm seus direitos subtraídos pela prática social.

Em consonância com o Decreto Federal no 5.296, de 2 de dezembro de 2004, "pessoa portadora de deficiência, além daquelas previstas na Lei $\mathrm{n}^{\circ} 10.690$, de 16 de junho de 2003, é a que possui limitação ou incapacidade para o desempenho de atividade e se enquadra nas seguintes categorias: deficiência física, mental, sensorial, orgânica, múltipla (surdo-cega e outros), visual e auditiva, como também outras modalidades (BATTES, 2006). 
O mesmo Decreto acima referenciado, além de descrever a deficiência estabelece em termos legais o entendimento do que é acessibilidade, in verbis:

Art. $8^{\circ}$ Para os fins de acessibilidade considera-se: I - acessibilidade: condição para utilização, com segurança e autonomia, total ou assistida, dos espaços, mobiliários e equipamentos urbanos, das edificações, dos serviços de transporte e dos dispositivos, sistemas e meios de comunicação e informação, por pessoa portadora de deficiência ou com mobilidade reduzida.

Salienta-se que o Capitulo IX, Art. 69 deste mesmo Decreto estabelece que: "Os programas nacionais de desenvolvimento urbano, os projetos de revitalização, recuperação ou reabilitação urbana incluirão ações destinadas à eliminação de barreiras arquitetônicas e urbanísticas, nos transportes e na comunicação e informação devidamente adequadas às exigências deste Decreto". Regulamentando a Lei n ${ }^{\circ} 10.436$, de 24 de abril de 2002, e o Art. 18 da Lei $\mathrm{n}_{-}^{\circ} 10.098$, de 19 de dezembro de 2000, o Decreto Federal ${ }^{\circ}$ 5.296, de 2 de dezembro de 2004 estabelece:

Art. $2^{-}$Para os fins deste Decreto, considera-se pessoa surda aquela que, por ter perda auditiva, compreende e interage com o mundo por meio de experiências visuais, manifestando sua cultura principalmente pelo uso da Língua Brasileira de Sinais - LIBRAS.

Parágrafo único. Considera-se deficiência auditiva a perda bilateral, parcial ou total, de quarenta e um decibéis $(\mathrm{dB})$ ou mais, aferida por audiograma nas frequências de $500 \mathrm{~Hz}, 1.000 \mathrm{~Hz}, 2.000 \mathrm{~Hz}$ e $3.000 \mathrm{~Hz}$.

No que se refere à educação o Decreto $\mathrm{n}^{0}$ 5.626, de 22 de Dezembro de 2005, Regulamenta a Lei no 10.436, de 24 de abril de 2002, que dispõe sobre a Língua Brasileira de Sinais - LIBRAS, e o Art. 18 da Lei no 10.098, de 19 de dezembro de 2000, in verbis:

Art. 14. As instituições federais de ensino devem garantir, obrigatoriamente, às pessoas surdas acesso à comunicação, à informação e à educação nos processos seletivos, nas atividades e nos conteúdos curriculares desenvolvidos em todos os níveis, etapas e modalidades de educação, desde a educação infantil até à superior.

$\S$ 1o Para garantir o atendimento educacional especializado e o acesso previsto no caput, as instituições federais de ensino devem:

I - promover cursos de formação de professores para:

a) o ensino e uso da LIBRAS;

b) a tradução e interpretação de LIBRAS - Língua Portuguesa; e

c) o ensino da Língua Portuguesa, como segunda língua para pessoas surdas;

II - ofertar, obrigatoriamente, desde a educação infantil, o ensino da Libras e também da Língua Portuguesa, como segunda língua para alunos surdos;

III - prover as escolas com:

a) professor de LIBRAS ou instrutor de LIBRAS;

b) tradutor e intérprete de LIBRAS - Língua Portuguesa;

c) professor para o ensino de Língua Portuguesa como segunda língua para pessoas surdas; e

d) professor regente de classe com conhecimento acerca da singularidade linguística manifestada pelos alunos surdos;

IV - garantir o atendimento às necessidades educacionais especiais de alunos surdos, desde a educação infantil, nas salas de aula e, também, em salas de recursos, em turno contrário ao da escolarização;

V - apoiar, na comunidade escolar, o uso e a difusão de Libras entre professores, alunos, funcionários, direção da escola e familiares, inclusive por meio da oferta de cursos;

VI - adotar mecanismos de avaliação coerentes com aprendizado de segunda língua, na correção das provas escritas, valorizando o aspecto semântico e reconhecendo a singularidade linguística manifestada no aspecto formal da Língua Portuguesa; 
VII - desenvolver e adotar mecanismos alternativos para a avaliação de conhecimentos expressos em Libras, desde que devidamente registrados em vídeo ou em outros meios eletrônicos e tecnológicos;

VIII - disponibilizar equipamentos, acesso às novas tecnologias de informação e comunicação, bem como recursos didáticos para apoiar a educação de alunos surdos ou com deficiência auditiva.

Como se pode deduzir do acima exposto, para que o surdo na condição de vítima ou réu tenha seus direitos respeitados, é preciso que os distintos sistemas de ensino sejam responsabilizados pela sua formação cidadã, levando em conta o direito de "ser diferente", como bem estabelece o Art. 26 do Decreto n 5.626 de 22 de dezembro de 2005, in verbis:

\begin{abstract}
A partir de um ano da publicação deste Decreto, o Poder Público, as empresas concessionárias de serviços públicos e os órgãos da administração pública federal, direta e indireta devem garantir às pessoas surdas o tratamento diferenciado, por meio do uso e difusão de LIBRAS e da tradução e interpretação de LIBRAS Língua Portuguesa, realizados por servidores e empregados capacitados para essa função, bem como o acesso às tecnologias de informação, conforme prevê o Decreto no 5.296 , de 2004.

$\S 1^{\circ}$ As instituições de que trata o caput devem dispor de, pelo menos, cinco por cento de servidores, funcionários e empregados capacitados para o uso e interpretação da LIBRAS.
\end{abstract}

No sentido de garantir o que estabelece o Art. 26 do Decreto ${ }^{\circ} 5.626$ supra, em seu Art. 28 consta que:

os órgãos da administração pública federal, direta e indireta, devem incluir em seus orçamentos anuais e plurianuais dotações destinadas a viabilizar ações previstas neste Decreto, prioritariamente as relativas à formação, capacitação e qualificação de professores, servidores e empregados para o uso e difusão da LIBRAS e à realização da tradução e interpretação de LIBRAS - Língua Portuguesa, a partir de um ano da publicação deste Decreto.

Segundo Santos, Santos Filho; Santo Oliveira (2010) apesar de que seja notória a presença de previsão orçamentária no orçamento, há obrigatoriedade de capacitação de professores, conforme o que estabelece o Art 30 do aludido Decreto, in verbis:

Os órgãos da administração pública estadual, municipal e do Distrito Federal, direta
e indireta, viabilizarão as ações previstas neste Decreto com dotações específicas em
seus orçamentos anuais e plurianuais, prioritariamente as relativas à formação,
capacitação e qualificação de professores, servidores e empregados para o uso e
difusão da LIBRAS e à realização da tradução e interpretação de LIBRAS - Língua
Portuguesa, a partir de um ano da publicação deste Decreto.

Recorda-se aqui que LIBRAS é a sigla de Língua Brasileira de Sinais, difundida pela Federação Nacional de Educação e Integração de Surdos (FENEIS) para procedimentos satisfatórios e prazerosos em audiências. Há sérias dificuldades enfrentadas pelos deficientes auditivos estando eles em audiência, visto que as pessoas ali, via de regra, não sabem como comunicar-se a não ser por gestos e mímicas, às vezes com auxilio de familiares. Na verdade isso ainda ocorre por descumprimento da Lei $\mathrm{n}^{\circ}$ 10.436, de 24 de Abril 2002 que estabelece:

Art. $1^{\circ}$ É reconhecida como meio legal de comunicação e expressão a Língua Brasileira de Sinais - LIBRAS e outros recursos de expressão a ela associados.

Parágrafo único. Entende-se como Língua Brasileira de Sinais - LIBRAS a forma de comunicação e expressão, em que o sistema linguístico de natureza visual-motora, 
com estrutura gramatical própria, constituem um sistema linguístico de transmissão de ideias e fatos, oriundos de comunidades de pessoas surdas do Brasil.

Art. $2^{\underline{o}}$ Deve ser garantido, por parte do poder público em geral e empresas concessionárias de serviços públicos, formas institucionalizadas de apoiar o uso e difusão da Língua Brasileira de Sinais - LIBRAS como meio de comunicação objetiva e de utilização corrente das comunidades surdas do Brasil.

Art. $3^{\circ}$ As instituições públicas e empresas concessionárias de serviços públicos de assistência à saúde devem garantir atendimento e tratamento adequado aos portadores de deficiência auditiva, de acordo com as normas legais em vigor.

Como se pode denotar, quem deveria fiscalizar a aplicação da Lei não a cumpre, no caso em que os deficientes auditivos são réus ou vítimas nos Tribunais de Justiça.

$\mathrm{O}$ surdo quer e merece respeito, porque ele se reconhece como parte do meio, como ser humano detentor de deveres e direitos. A Língua Brasileira de Sinais é a linguagem mais utilizada pelos surdos, e é reconhecida pela Lei Estadual- MS n ${ }^{\circ} 1.693$ de 12 de Setembro de 1996, como meio de comunicação objetiva de uso corrente, além das leis nacionais que instituíram, reconheceram e regulamentaram a LIBRAS. De acordo com essa lei estadual o Estado de Mato Grosso do Sul deve treinar pessoal de seu quadro de servidores, diretamente ou por convênios, objetivando prover as repartições públicas voltadas para o atendimento externo de profissionais que possam compreender a comunidade surda.

Assim como a língua falada, a língua de sinais não é universal, cada país possui seu tipo de expressão e linguagem, por exemplo: no Brasil utiliza-se LIBRAS, em Portugal LGP Língua Gestual Portuguesa, em Angola predomina a LAS - Língua Angolana de Sinais. Ou seja, LIBRAS é tão importante quanto o Português e outros idiomas, por isso devem ser respeitados como tal. Michaelis (2000, p.134) defende a importância da valorização de LIBRAS afirmando que:

Uma língua que foi criada e é utilizada por uma comunidade específica de usuários, que é transmitida de geração em geração, e que muda - tanto estrutural como funcionalmente - com o passar do tempo. Ora, qualquer língua pode ser considerada como tal, independente da modalidade que utiliza.

Para o homem a comunicação é vital, de acordo com Bernardino (2000) uma das principais maneiras de construir ou identificar uma cultura, é o uso de uma determinada linguagem, por meio dela são expostos medos, desejos, emoções e crenças. Logo se pode afirmar que a comunicação é fundamental e quando o individuo não consegue ser entendido, chega-se ao ponto de ficar impaciente. $\mathrm{O}$ mesmo ocorre com o surdo, existem características que são atribuídas a eles, algumas delas são: agressividade, timidez, falta de educação. Isso acontece, na maioria das vezes, quando existe a limitação com relação à comunicação.

Não há inclusão social sem que haja comunicação, a carência da mesma acarreta diversos tipos de males para o deficiente auditivo, ainda marginalizado apesar de tantos exemplos de competência por parte dos mesmos. A primeira instituição a colaborar para a inclusão dos surdos no Brasil foi o Instituto Nacional de Educação aos Surdos (INES), no Rio de Janeiro, fundado em 1857 pelo professor francês Hernest Huet (surdo), com o apoio do Imperador. Inicialmente funcionava como um asilo para surdos do sexo masculino, visto que muitos deles eram abandonados pelas próprias famílias (MEDEIROS, 2015).

O profissional intermediador entre o português falado e as LIBRAS denomina-se intérprete de sinais. Segundo Quadros (2004), “o intérprete de sinais é uma pessoa que 
interpreta de uma dada língua de sinais para outra língua, ou desta outra língua para uma determinada língua de sinais". Para exercer essa profissão é preciso entender as necessidades, "vestir a camisa" na luta pelos direitos a acessibilidade e inclusão do surdo na sociedade. Algumas instituições que promovem cursos de LIBRAS classificam os estágios de aprendizagem dos cursistas em níveis: básico, intermediário, avançado, prático de interpretação e deverá ser aprovado na proficiência em LIBRAS pelo Ministério da Educação. Porém, para que seja possível a atuação no mercado de trabalho é necessário um certificado ou declaração de uma instituição ligada à comunidade surda, como por exemplo, a Federação Nacional de Educação e Integração dos Surdos.

\section{Os processos criminais no tribunal de justiça e ministério público}

A etimologia das palavras ajuda entender não apenas o conceito literal, mas também o funcional. No caso da expressão processo criminal, Barbosa (2004, p.53) assevera que: "o termo processo é derivado do latim processsus de procedere. Provém do verbo proceder que, em geral, exprime a ordem ou a sequência de atos variados, com o escopo de um único fim. É fato em seguimento". Em outros termos "[...] o processo é uma série de atos, praticados pelos órgãos judiciários e pelas partes, necessários à produção de um resultado final, que é a concretização do direito, ou seja, sua realização no caso concreto e em última instância" (ROCHA, 1996, p.209, SANTOS, SANTOS FILHO; SANTO OLIVEIRA, 2010, on line).

Sem considerar as áreas e especificidades do Direito, como no caso o Processo Civil, Processo Trabalhista, Processo Administrativo, Processo Penal etc. é possível afirmar que a ideia genérica de processo implica ação judicial, a sequência de atos previamente estabelecidos em conformidade com a legislação, objetivando o alcance de um dado resultado jurídico. Em sentido mais simples pode ser entendido como o conjunto de documentos apresentados para se resolver alguma questão.

O Processo Penal, particularmente, é uma área do direito público, em que um determinado Estado exerce o seu poder de forma a aplicar o direito penal em casos específicos. O Processo Penal é regido pelo Código do Processo Penal. O Direito Processual Penal tem como objeto de estudo a legitimação da autoridade do Estado de aplicar penas no decorrer de um processo penal. Além do mais visa a verdade dos fatos mediante as atividades das partes, ora aplicando penas aos culpados, e ora absolvendo os inocentes (PROCESSO PENAL, 2015).

O Processo Penal comporta finalidade direta e indireta. Para Medeiros (2015) a finalidade direta se refere às normas do processo, visto que o Processo Penal é um conjunto de atos cuja forma, tempo, lugar e sucessão são regulados pelo direito processual. A finalidade indireta refere-se à aplicação da lei penal. Aplicar a lei penal não significa, tão somente, punir o culpado, significa também absolver o inocente e garantir sua liberdade. Para tanto é indispensável procurar a verdade real. Perseguir a verdade real quanto ao fato, quanto à personalidade do agente, quanto aos seus antecedentes, por meio do processo, é indispensável para que se aplique a lei penal. A persecução da verdade real é a forma pela qual o direito processual penal atinge seu fim indireto (aplicação da lei penal). 
Esse instrumento Jurisdicional é dividido em três fases: o inquérito policial; instrução de caráter facultativo e o julgamento. O Inquérito policial visa investigar se foi praticado um crime e, na afirmativa, quem foi o seu autor. Essa fase é conduzida pelo Ministério Público, que pode ser coadjuvado por órgãos de polícia criminal, como a Polícia Judiciária, a Polícia de Segurança Pública ou a Guarda Nacional Republicana. Tendo como objetivo sujeitar o suspeito a julgamento perante o tribunal, para aplicação de uma pena. A instrução é uma fase intermediária de caráter facultativo que leva o acusado a uma arguição para que interrompa ou não a realização do julgamento pelo Juiz. A terceira fase é o julgamento que perante o tribunal, o suspeito, o réu é confrontado com a acusação ou com a pronúncia. Da mesma, constam os casos que ele alegadamente terá praticado e o crime que lhe é imputado (SANTOS; SANTOS FILHO; SANTO OLIVEIRA, 2010, on line).

\section{O julgamento dos surdos no âmbito processual criminalístico}

Para bem entender o que se propõe neste tópico é importante saber que a linguagem é responsável pela regulação da atividade psíquica humana, pois é ela que permeia a estruturação dos processos cognitivos. Assim, é assumida como constitutiva do sujeito, pois possibilita interações fundamentais para a construção do conhecimento (VYGOTSKI, 2001 apud LOPES, et al., 2015 ). É por meio do contato com a linguagem que o sujeito se constitui. Já para as pessoas surdas, esse contato é prejudicado, podendo trazer consequências emocionais, sociais e cognitivas. Assim, os sujeitos surdos pela defasagem auditiva enfrentam dificuldades para entrar em contato com a língua do grupo social no qual estão inseridos (GÓES, 1996 apud LOPES, et al.,2015 ).

O interrogatório é analisado ora meio de conservação, ora meio de avaliação, ora respectivamente meio de prova e de defesa. Atualmente a posição mais aceita pelos doutrinadores e a jurisprudência é a última, de ser o interrogatório meio de prova e de defesa. Mirabete (1998, p. 282) sustenta que,

[...] sendo o interrogatório ao menos em parte, meio de defesa, o acusado pode mentir e negar a verdade. Não há um verdadeiro direito de mentir, tanto que as eventuais contradições em seu depoimento podem ser apontadas para retirar qualquer credibilidade das suas respostas. Mas o acusado, não presta compromisso de dizer a verdade, como testemunha, e sua mentira não constitui crime, não é ilícito. O réu é livre para mentir porque, se o fizer, não sofrerá nenhuma sanção. Essa liberdade, porém, é concedida apenas em benefício de sua defesa, pois se ele atribui a si próprio crime inexistente ou praticado por outrem, comete o delito de autoacusação falsa [...].

$\mathrm{O}$ ato interrogatório representa momento ímpar para o réu e para a vítima, notadamente, quando se tratar de um deficiente auditivo. É quando ele pode se declarar de modo a promover sua autodefesa, apresentando sua versão dos fatos. É claro que esse momento representa oportunidade especial para que o magistrado possa criar convicções acerca do interrogado.

Salienta-se que o ato interrogatório, pode resultar comprometido quando não há a presença de um competente intérprete em LIBRAS, visto que a pessoa deficiente auditiva não tem em principio, condições de entender a ritualística estabelecida. Até mesmo o direito de ficar calado e não gerar provas contra si mesmo pode ser mal entendido.

Outra questão não menos importante é abordada por Tornaghi, (1978, p.20), quando afirma que "[...] o réu pode até mentir. Não se trata de um direito de mentir, nem há 
que falar em direito (subjetivo), neste caso. O que há é que a mentira do réu não constitui um crime, não é ilícito [...]”. Isso está relacionado com a ideia de não gerar prova contra si mesmo. Não há dúvidas de que tudo isso implica extremado cuidado do magistrado para não formar juízo errôneo ou viciado pelo fato de que o réu ou a vítima seja deficiente auditivo.

O exposto, trás à baila uma vez mais a necessidade do profissional tradutorintérprete em LIBRAS quando do julgamento de um deficiente auditivo. Segundo Quadros, (2004) tradutor-intérprete de língua de sinais é a pessoa que traduz e interpreta a língua de sinais para a língua falada e vice-versa em quaisquer modalidades que se apresentar, oral ou escrita.

No caso de condenação de um deficiente auditivo, a preocupação está em se saber se haverá ou não a assistência de um tradutor-intérprete. Segundo Cecílio e Souza (2015) é preciso lembrar que a língua e o uso de uma linguagem são as principais formas de acesso ao mundo. A língua permite a conversação, troca de ideias, aquisição de conhecimento e interação entre as pessoas. Compreender uma língua, possuir uma linguagem é ter acesso ao poder em nossa sociedade; além de nos identificar enquanto pertencentes a um determinado grupo. Falar uma determinada língua é expressar através dela toda a gama de significados em que aquele grupo social e/ou cultural está imbuído.

Em uma audiência em que uma pessoa surda é infrator de alta periculosidade, podemse tiras as algemas, sabendo-se que ela utiliza as mãos para falar?

Disciplinando o uso de algemas pela polícia, em 22.08 .2008 , o Supremo Tribunal
Federal editou a Súmula Vinculante 11 , do seguinte teor: Só é lícito o uso de
algemas em casos de resistência e de fundado receio de fuga ou de perigo à
integridade física própria ou alheia, por parte do preso ou de terceiros, justificada a
excepcionalidade por escrito, sob pena de responsabilidade disciplinar, civil e penal
do agente ou da autoridade e de nulidade da prisão ou do ato processual a que se
refere, sem prejuízo da responsabilidade civil do Estado (SILVEIRA, 2009, p. 13).

Outro cuidado que deve ser tomado quando do julgamento de um surdo é a questão da confiança no tradutor-intérprete visto que pode haver equívocos. A única garantia nesse sentido é o Código de Ética que rege a profissão, que estabelece:

Artigo 1: São deveres fundamentais do intérprete. O intérprete deve ser uma pessoa de alto caráter moral, honesto, consciente, confidente e de equilíbrio emocional. Ele guardará informações confidenciais e não poderá trair confidencias, as quais foram confiadas a ele;

Artigo 2: O intérprete deve manter uma atitude imparcial durante o transcurso da interpretação, evitando interferências e opiniões próprias, a menos que seja requerido pelo grupo a fazê-lo;

Artigo 3: O intérprete deve interpretar fielmente e com o melhor da sua habilidade, sempre transmitindo o pensamento, a intenção e o espírito do palestrante. Ele deve lembrar dos limites de sua função e não ir além da responsabilidade;

Artigo 4: O intérprete deve reconhecer seu próprio nível de competência e ser prudente em aceitar tarefas, procurando assistência de outros intérpretes e/ou profissionais, quando necessário, especialmente em palestras técnicas;

Artigo 5: O intérprete deve adotar uma conduta adequada de se vestir, sem adereços, mantendo a dignidade da profissão e não chamando atenção indevida sobre si mesmo, durante o exercício da função.

Artigo 6: O intérprete deve ser remunerado por serviços prestados e se dispor a providenciar serviços de interpretação, em situações onde fundos não são possíveis; Artigo 7: Acordos em níveis profissionais devem ter remuneração de acordo com a tabela de cada estado, aprovada pela FENEIS. 
Artigo 8: O intérprete jamais deve encorajar pessoas surdas a buscarem decisões legais ou outras em seu favor;

Artigo 9: O intérprete deve considerar os diversos níveis da Língua Brasileira de Sinais bem como da Língua Portuguesa;

Artigo 10: Em casos legais, o intérprete deve informar à autoridade qual o nível de comunicação da pessoa envolvida, informando quando a interpretação literal não é possível e o intérprete, então terá que parafrasear de modo claro o que está sendo dito à pessoa surda e o que ela está dizendo à autoridade;

Artigo 11: O intérprete deve procurar manter a dignidade, o respeito e a pureza das línguas envolvidas. Ele também deve estar pronto para aprender e aceitar novos sinais, se isso for necessário para o entendimento;

Artigo 12: O intérprete deve esforçar-se para reconhecer os vários tipos de assistência ao surdo e fazer o melhor para atender as suas necessidades particulares.

Artigo 13: Reconhecendo a necessidade para o seu desenvolvimento profissional, o intérprete deve agrupar-se com colegas profissionais com o propósito de dividir novos conhecimentos de vida e desenvolver suas capacidades expressivas e receptivas em interpretação e tradução.

Parágrafo único. O intérprete deve esclarecer o público no que diz respeito ao surdo sempre que possível, reconhecendo que muitos equívocos (má informação) têm surgido devido à falta de conhecimento do público sobre a área da surdez e a comunicação com o surdo.

Em vista do exposto, é necessário vencer o dilema institucional da dificuldade de conciliar o princípio jurídico formal da "igualdade perante a lei" com "desigualdade diante da realidade". O indivíduo em pleno gozo do status civitatis - comumente chamado cidadania é aquele que a Constituição reconhece como merecedor de direitos e garantias fundamentais: direitos do exercício da liberdade individual, direitos civis e políticos e direitos sociais (CUNHA, 2009; SANTOS; SANTOS FILHO; SANTO OLIVEIRA, 2010, on line). Rotular os deficientes como pessoas com problemas mentais traz uma retórica de preconceitos e julgamentos equivocados, pronunciados por autoridades que desconhecem os conceitos de surdez, LIBRAS e Tradutor-intérprete de LIBRAS.

\section{CONSIDERAÇÕES FINAIS}

As reflexões acerca da inclusão dos Deficientes Auditivos nos Tribunais de Justiça nos ajudam a perceber a importância do assunto para a sociedade. As mudanças introduzidas pela Legislação específica de proteção e acolhimento do deficiente auditivo representa um avanço extraordinário no processo de inclusão dessas pessoas, em todos os segmentos sociais. Ainda que muitas organizações e instituições desconheçam o rol normativo a respeito da pessoa surda, a legislação representa um meio eficaz dos surdos buscarem seus direitos, incluindo um julgamento justo em um Tribunal.

O responsável pelos Processos Criminais deve inteirar-se sobre a legislação específica que trata dos surdos e adotar uma conduta condizente com a proteção e garantia dos seus direitos. É preciso que novas pesquisas sejam desenvolvidas no sentido de melhor elucidar essas questões e o surdo possa assumir na sociedade uma postura mais crítica e participativa.

Acreditamos que no futuro, a importância dos Deficientes Auditivos - das pessoas surdas - seja verdadeiramente reconhecida e aquilo que está sendo oferecido, a eles no presente, seja efetivado de forma coerente, e que não seja negligenciado, posto que os mesmos em muitos casos podem ser excluídos.

\section{REFERÊNCIAS}


BARBOSA, Lina Fiuza Caminha. Definição de processo. In: Revista jurídica da FAL: Faculdade Integrada do Ceara, v. 3, nº 3 ( mar. 2004).

BATTES, Ricardo Lovatto (org.) Direito à educação: subsídios para a gestão dos sistemas educacionais - orientações gerais e marcos legais.2. ed. Brasília: MEC, SEESP, 2006.

BERNARDINO, Elidéia Lúcia. Absurdo ou lógica? Os surdos e sua produção linguística. Belo Horizonte: Profetizando Vida, 2000.

BRASIL. Lei $n^{\circ}$ 10.436, de 24 de abril de 2002. Disponível em:

<http://www.planalto.gov.br/ccivil_03/leis/2002/110436.htm>. Acesso em: 17/11/2017.

Lei $n^{o} 10.690$, de 16 de junho de 2003. Disponível em:

<http://www.planalto.gov.br/ccivil_03/leis/2003/L10.690.htm>. Acesso em: 20/02/2017.

Decreto Federal no 5.296, de 2 de dezembro de 2004. Disponível em:

<http://www.planalto.gov.br/ccivil_03/_ato2004-2006/2004/decreto/d5296.htm>. Acesso em: $<02 / 02 / 2017\rangle$.

.Decreto Federal $n^{\circ} 5.626$ de 22 de dezembro de 2005. Disponível em:

http://www.planalto.gov.br/ccivil_03/leis/2005/L5.626.htm>. Acesso em: 17/11/2017.

CAMPO GRANDE- MS. Lei $n^{\circ} 2.997 / 93$ de 10 de Novembro de 1993. Disponível em: <https://cm-campo-grande.jusbrasil.com.br/legislacao/252126/lei-2997-93>. Acesso em: $17 / 11 / 2017$.

CECÍLIO, G. M. e SOUZA, C. D. de. Identidades transitastes: o desencaixe do deficiente auditivo nos discursos de/sobre surdos e ouvintes. Revista virtual de cultura surda $e$ diversidade. Arara Azul [s/d].

CUNHA, Djason B. Della. Política criminal e direitos humanos: agravamento e alternativas penais. In: Ágora: Revista Jurídica da FAL. v.5, n.5 (2009). Faculdade de Natal. Curso de Direito da FAL; Núcleo de Pesquisa em Direito da FAL. Natal: RN Econômico, 2009.

FERREIRA, M. E. C.; GUIMARÃES, M. Educação inclusiva. RJ: DO\&A, 2003.

GRINOVER, A. P. Interrogatório do réu e direito ao silêncio. Ciência Penal, São Paulo, v. 3, n. 1, p. 29, 1976.

LOPES, Guilherme et al. A inclusão do aluno surdo no âmbito escolar. Disponível em: <http://www.efdeportes.com/efd186/a-inclusao-do-aluno-surdo-no-ambito-escolar.htm>. Acesso em: 28.12.15.

MAGALHÃES, Leny Mrech. Educação Inclusiva: Realidade ou Utopia?. São Paulo. 1999.

MEDEIROS, F. M. Direito Processual Penal. Necessidade e importância. Autonomia. Finalidade. Disponível em: 〈http://www.ambito-juridico.com.br>. Acesso em: 27.12.15. 
MICHAELIS. Moderno dicionário da língua portuguesa. São Paulo: Companhia Melhoramentos, 2000.

MIRABETE, Julio Fabbrini. Processo penal. 8 ed. rev.atual. São Paulo. Atlas. 1998.

NORONHA, E. Marganhães. Curso de direito processual penal. 23. ed. SP: Saraiva. 1995.

MOURA, Maria Thereza Rocha de Assis; MORAIS, Maurício Zanoide de. Direito ao silêncio no interrogatório. Revista Brasileira de Ciências Criminais, São Paulo, v. 2, n. 6, p. 137, abr./jun. 1994.

PIERUCCI, Antônio Flávio. Ciladas da diferença. São Paulo: USP, 1999. Disponível em: $<$ http://www.webartigos.com/artigos/tribunal-de-justica-o-julgamento-inclusivo-dossurdos/38094/>. Acesso em: 26.12.15.

PROCESSO PENAL. Significado de processo. Disponível em: <http://www.significados.com.br/processo/>. Acesso em: 27.12.15

QUADROS, Ronice Müller. O tradutor e intérprete de língua brasileira de sinais e língua portuguesa / Secretaria de Educação Especial. Programa Nacional de Apoio à Educação de Surdos - Brasília: MEC; SEESP, 2004.

ROCHA, José de Albuquerque. Teoria geral do processo. 3 ed. São Paulo, 1996.

SANTOS, Angevaldo Matos, SANTOS FILHO, Genivaldo Oliveira, OLIVEIRA Rozilda Ramos dos. Tribunal de Justiça: o julgamento inclusivo dos surdos. Disponível em: $<$ http://www.webartigos.com/artigos/tribunal-de-justica-o-julgamento-inclusivo-dossurdos/38094/>. Acesso em: 26.12.15.

SILVEIRA, Paulo Fernando. Algemas ? seu uso e a súmula vinculante 11 do STF: regra ou exceção?: Revista Jurídica UNIJUS / Universidade de Uberaba, Ministério Público do Estado de Minas Gerais, v. 1, n.1 (1998). Uberaba: UNIUBE, 1998.

TORNAGHI, Helio Basto. Instituição do Processo Penal. 2 ed. rev.atual. São Paulo: Saraiva. 1978.

Recebido 13/04/2015

Aprovado 11/2016 